\title{
The assessment of the time-lapse between toxic exposure and examination in the Toxicology Department in pediatric severe acute poisoning
}

\author{
Cristina-Daniela ENACHE ${ }^{1}$, Cristina lolanda VIVISENCO ${ }^{2,3}$, Dora Andreea BOGHITOIU ${ }^{2,3}$, \\ Madalina Elena PETRAN ${ }^{2,4}$, Viorela Gabriela NITESCU ${ }^{2,3}$, Coriolan Emil ULMEANU2,3, \\ Anca Angela SIMIONESCU ${ }^{5,6}$, Vlad DIMA7, Simona STANCA ${ }^{2,3}$
}

${ }^{1}$ Emergency Unit Department, "Grigore Alexandrescu" Emergency Children's Hospital, Bucharest, Romania ${ }^{2}$ Department of Toxicology, "Grigore Alexandrescu" Emergency Children's Hospital, Bucharest, Romania

${ }^{3}$ Department of Pediatrics, "Carol Davila" University of Medicine and Pharmacy, Bucharest, Romania ${ }^{4}$ Department of Biochemistry, "Carol Davila" University of Medicine and Pharmacy, Bucharest, Romania

${ }^{5}$ Department of Obstetrics and Gynecology,

"Carol Davila" University of Medicine and Pharmacy, Bucharest, Romania

${ }^{6}$ Department of Obstetrics and Gynecology, Filantropia Clinical Hospital, Bucharest, Romania

${ }^{7}$ Department of Neonatology, Filantropia Clinica Hospital, Bucharest, Romania

\begin{abstract}
The exposure of the pediatric population to xenobiotics is an important public health problem because children are particularly vulnerable to the unfavorable consequences of intoxications due to their age-related peculiarities, having limited physiological reserves, and poorly developed metabolic pathways.

Numerous studies emphasize the importance of targeted therapeutic intervention and as soon as possible in patients with severe acute intoxications that associate signs of cardiogenic shock due to the severity of cases and the risk of adverse evolution.

This paper presents a statistical analysis of the time-lapse impact between exposure to the toxicant and the toxicological examination on the patient's prognosis. Its purpose is to identify both qualitative and quantitative correlations between a series of parameters associated with unfavorable evolution and the time elapsed until the specific toxicological management is performed.
\end{abstract}

Keywords: pediatrics, poisoning, toxicology, adverse events, cardiogenic shock, statistical analysis

\section{INTRODUCTION}

Acute intoxications are a growing emergency pathology and a significant cause of hospitalization worldwide. A study conducted in the Department of Toxicology of the Grigore Alexandrescu Children's Emergency Hospital Bucharest between 2004 and 2008 quantified a prevalence of cases of acute intoxication of $10.5 \%$ of all non-surgical pediatric patients admitted to the clinic [1]. Ten years later, a study in the same clinic, in similar conditions, in the period 2014-2020 evaluated an increased prevalence of cases of acute intoxications in a percentage of $12.15 \%$ [2].

Rapid recognition and prompt intervention are essential measures in managing severe acute intoxications complicated by cardiogenic shock. The shock 
mortality rate of pediatric patients is much lower than that of adults, and a significant improvement is associated with the early intervention [3].

Existing antitoxic protocols recommend that critically ill patients with acute intoxication be managed by a multidisciplinary team supported by a clinical toxicologist, usually located in a large academic or antitoxic center. In its absence in the medical team, the doctors who manage the case are forced to use telephone recommendations, online medical databases, or reference manuals. Severe intoxications should be referred to regional centers after patient stabilization [4].

Given the importance of toxicologists' management in severe poisoning corroborated with their small number, the recommended approach in our country for territorial hospitals is to stabilize the patient and establish the first therapeutic maneuvers [5]. The attending physician who takes care of the patient at the first presentation can always request the specialized indications from the regional hospital or the regional antitoxic center. Later, it will be transferred to a regional hospital equipped with a Toxicology Department.

The lack of specialized medical staff prevents hospitals from providing optimal care to intoxicated patients; limited pharmacological resources and medical devices also contribute to this situation. A tiny number of hospitals can provide the attending physician with all the necessary medication and antidotes that are sometimes needed in sufficient quantities. Most hospital units have the kits for the qualitative determination of a limited amount of toxic, and for an exhaustive evaluation, it is necessary to collaborate with remote toxicological centers [4].

\section{OBJECTIVES}

The paper's main objective is to quantify the impact of the transfer time on critically ill patients from a territorial unit to a hospital with a Toxicology Department. To achieve its goals, a detailed statistical study was performed which considers as independent variables parameters associated with unfavorable evolution: coma, the need for orotracheal intubation (IOT) and mechanical ventilation, admission to the ICU, need of inotropic support, cardio-respiratory arrest, and death and as the dependent variable, the time elapsed from the toxic exposure until the admission in a toxicology department.

\section{MATERIAL AND METHOD}

Data base for this research has been obtained in the Department of Toxicology of the "Grigore Alexandrescu“ Emergency Children's Hospital Bucharest. There were analyzed cases of acute poisoning hospitalized between January 2014 and December 2020, amounting to 7666 patients. Have been researched clinical observation files of the patients intoxicated and among them have been identified those where the etiologic agent was a cardiotropic substance, so the potential for evolution to cardiogenic shock, obtaining a group of 1396 patients. After a thorough analysis of the patients at risk evolution, have been selected those that have shown from admission or in evolution signs of cardiogenic shock, obtaining a batch of 50 of the cases.

Each of the 50 patients included in the study group presented at least one of the following diagnostic criteria for cardiogenic shock:

- weakly filiform or absent pulse in the major arteries

- capillary recoloration time over 2 seconds

- low blood pressure

- cold, cyanotic, marbled extremities

- decrease of diuresis below $1 \mathrm{ml} / \mathrm{kgc} / \mathrm{hour}$

- altered mental status.

For each patient from the selected group, the period from the toxic exposure until the toxicological examination was recorded. For selected cases, it was also noted the period that the patient arrived at the intermediate hospital to receive the emergency approach and later to be transferred to our clinic.

The collected data were processed using the IBM SPSS program. The obtained results were represented as a percentage, frequency, standard deviation, variations, average and median, depending on the situation and concordance with the latest recommendation for small samples studies [6].

The $t$ (Student) test for independent variables with a marginal error of $5 \%$ was used to evaluate the differences in the means representing the time from ingestion to the presentation at the first medical unit and the time from ingestion to transfer to a toxicology department.

The bivalent Pearson coefficient was used to test the statistical correlation between two variables. Two levels of statistical significance of 0.01 and 0.05 , which correspond to marginal errors of $1 \%$ and $5 \%$, were considered.

\section{RESULTS}

In the following analysis, data collected noticed the existence of two samples in the study group. One of these is composed of 21 patients that presented using personal means or by ambulance, directly in the Emergency Unit of Grigore Alexandrescu Children's Emergency Hospital, equipped with Toxicology Department, so the possibility to be taken care of by a specialist. The second sample consists of 29 cases in which the primary care was performed in a medical care unit without a 
Toxicology Department and be transferred stabilized at SCUC Grigore Alexandrescu. The analysis comparing the presentation period of cases according to the type of hospital is detailed in Table 1.

TABLE 1. Distribution of the period to the first examination according to the type of hospital the patient addressed

\begin{tabular}{|l|c|c|c|c|}
\hline & $\begin{array}{c}\text { The type of } \\
\text { hospital }\end{array}$ & $\begin{array}{c}\text { No. of } \\
\text { Patients }\end{array}$ & Media & $\begin{array}{c}\text { Standard } \\
\text { deviation }\end{array}$ \\
\hline $\begin{array}{l}\text { Time-lapse } \\
\text { between } \\
\text { ingestion } \\
\text { and } \\
\text { examination } \\
\text { (min) }\end{array}$ & $\begin{array}{c}\text { With } \\
\text { Toxicology }\end{array}$ & 21 & 262.50 & 210,403 \\
\cline { 2 - 5 } & $\begin{array}{c}\text { Without } \\
\text { Toxicology }\end{array}$ & 29 & 250.54 & 214,028 \\
\hline
\end{tabular}

Comparing the mean time interval between exposure to the toxicant and the moment when the first medical gestures are performed on the patient, regardless of whether they are specialized or just maneuvers to stabilize the patient, it is observed that both types of patients are medically managed at similar times. To determine if the mean of the time intervals is statistically significant, a Student's t-test for independent variables was performed (table 2). It noted that there is no statistically significant difference between patients who presented to a hospital with toxicology department $\mathrm{t}_{\text {medium }}=262.50 \pm 210.4 \mathrm{~min}$, respectively those that were presented at a hospital without department of toxicology $\mathrm{t}_{\text {medium }}=250.54 \pm 214 \mathrm{~min}, \mathrm{t}(48)=0.132$, $\mathrm{p}=0.05$.

Interesting is that the time of those presenting directly in a hospital equipped with a Toxicology Department is higher (262.50 compared to 250.54 minutes) than to those who require a transfer, a situation that would be able to be explained by the fact that some of the caregivers provide children with personal means to a hospital ranked higher instead of requesting the ambulance service. A descriptive analysis of these patients is presented in Table 3.

The mean time patients received first aid, whether in a Toxicology Department or a lower-ranking health facility without a toxicologist, was 256,56 minutes, or 4 hours and 17 minutes. Recording the extremes, the fastest has been examined a patient at 30 minutes after exposure, and the largest period to be handled a case has been 1440 minutes. Both patients have survived.

Further, we examined the presentation time to the Toxicology Department, considering the way patients arrived, directly or in following a transfer (table 4).

TABLE 4. Comparative analysis of the examination time in the Toxicology Department

\begin{tabular}{|l|l|l|l|l|}
\hline & $\begin{array}{l}\text { Transfer } \\
\text { from } \\
\text { another } \\
\text { hospital }\end{array}$ & $\begin{array}{l}\text { No. } \\
\text { Patients }\end{array}$ & Mean & $\begin{array}{l}\text { Std. } \\
\text { Deviation }\end{array}$ \\
\hline $\begin{array}{l}\text { Time-lapse } \\
\text { between exposure } \\
\text { and toxicological } \\
\text { examination (min) }\end{array}$ & YOT & 21 & 264.29 & 400,095 \\
\cline { 2 - 5 } & YES & 29 & 563.28 & 415,052 \\
\hline
\end{tabular}

A major difference between the two subgroups is observed when analyzing the time-lapse from toxic exposure to toxicological management. Mean presentation time to the hospital for the cases who came directly in Toxicology is 264.29 minutes, while those who came through transfer receive a toxicological examination after a time almost double, to 563.28 minutes. This difference is statistically significant $t(48)=0.014<0.05$, $\mathrm{p}=0.05$.

Further, it was investigated to what extent specialized care available in the two types of hospitals, given

TABLE 2. Independent Samples t-Test

\begin{tabular}{|l|l|c|c|c|c|c|c|}
\hline \multicolumn{2}{|c|}{} & \multicolumn{2}{|c|}{$\begin{array}{c}\text { Levene's Test } \\
\text { for Equality of } \\
\text { Variances }\end{array}$} & $\begin{array}{c}\text { t-test for } \\
\text { Equality of } \\
\text { Means }\end{array}$ & \multicolumn{2}{|c|}{ t-test for Equality of Means } \\
\cline { 3 - 9 } & $\mathrm{F}$ & Sig. & $\mathrm{t}$ & Df & $\begin{array}{c}\text { Sig. } \\
\text { (2-tailed) }\end{array}$ & $\begin{array}{c}\text { Mean } \\
\text { Difference }\end{array}$ \\
\hline $\begin{array}{l}\text { Time-lapse between } \\
\text { exposure and } \\
\text { examination (min) }\end{array}$ & $\begin{array}{l}\text { Equal variances } \\
\text { assumed }\end{array}$ & 1,613 & .210 & .132 & 48 & .896 & 11,964 \\
\cline { 2 - 9 } & $\begin{array}{l}\text { Equal variances are } \\
\text { not assumed }\end{array}$ & & & .119 & 26,398 & .906 & 11,964 \\
\hline
\end{tabular}

TABLE 3. Descriptive analysis of the two samples of patients

\begin{tabular}{|l|c|c|c|c|c|}
\hline & $\begin{array}{c}\text { The mean time of } \\
\text { the takeover }\end{array}$ & $\begin{array}{c}\text { No. of } \\
\text { patients }\end{array}$ & $\begin{array}{c}\text { Maximum } \\
\text { time }\end{array}$ & Median & $\begin{array}{c}\text { Minimum } \\
\text { time }\end{array}$ \\
\hline $\begin{array}{l}\text { The time-lapse between exposure } \\
\text { and the non-toxicological examination } \\
\text { (min) }\end{array}$ & 250.54 & 29 & 1440 & 120 & 30 \\
\hline $\begin{array}{l}\text { The time-lapse between exposure and } \\
\text { the toxicological examination (min) }\end{array}$ & 262.59 & 21 & 1740 & 300 & 60 \\
\hline
\end{tabular}


the existence of a toxicologist expert in the team, influences the prognosis of patients.

The Pearson coefficient of correlation has identified moderate-quality links between the status of the transferred patient and the unfavorable evolution parameters elected. The table below shows that the need to transfer a patient to receive the care of a toxicologist negatively impacts his prognosis. The patient transferred from a lower rank medical unit, as compared with the one who shows directly in Toxicology, has a statistically significantly greater risk that during hospitalization to associate coma (Pearson coefficient = $0.383, p=0.01$ ), be intubated and mechanically ventilated $(0.350, p=0.01)$ or to require admission in the $\operatorname{ICU}(0.372, p=0.01)$. No link between the transfer of the patient and his risk of death has been found.

Table 5 presents a qualitative analysis highlighting only the existence of a correlation between the transfer of the patient and the evolution during hospitalization. Because according to Table 4, the time necessary for a patient to receive the toxicological examination is almost double if he comes by transfer, aroused the necessity of quantifying the impact of this period on the patient's prognosis.

Table 6 investigated the time-lapse recorded from toxic exposure until the toxicologic examination, both for the sample of patients present directly in Toxicology and those coming by transfer. Analysis of Pearson cor- relation identified moderate links of the parameters of unfavorable evolution to cases coming through transfer. Thus, the greater the time-lapse the patient receives the toxicological examination, the greater the risk he will associate in evolution coma or be intubated and mechanically ventilated, coefficients Pearson calculated as 0.393 and 0.313 for $p=0.01$.

The results presented, emphasizing the risks to which a transferred patient is exposed, must be treated with caution and not supporting the retention of patients in the territorial hospital even if there is the possibility of supervising the treatment by a toxicologist from a distance.

\section{DISCUSSIONS}

The accuracy of treatment and medical care received by patients with intoxications was the main objective of several studies, given that there is no toxicologist in the medical team and without the possibility for on-call consultation [1,7-10]. One study concludes that in 29 out of 60 deaths caused by acute poisoning, there were management errors, according to the evaluation of a toxicologist expert [5]. Two other studies found that $20-24 \%$ of inpatient deaths could have been prevented if a toxicologist had been consulted $[4,6]$.

A study also demonstrates that medical care by a physician toxicologist made directly at the bedside re-

TABLE 5. Pearson Coefficients to establish the correlation between parameters of unfavorable evolution to the patient transferred in a Toxicology Department

\begin{tabular}{|c|c|c|c|c|c|c|c|}
\hline & & $\begin{array}{l}\text { Transferred } \\
\text { patient }\end{array}$ & IOT & Coma & $\begin{array}{c}\text { Cardio- } \\
\text { respiratory stop }\end{array}$ & $\begin{array}{c}\text { ATI } \\
\text { admission }\end{array}$ & Exitus \\
\hline \multirow{3}{*}{$\begin{array}{l}\text { Transferred } \\
\text { patient }\end{array}$} & $\begin{array}{l}\text { Pearson } \\
\text { Correlation }\end{array}$ & 1 & $.350^{* *}$ & $.383^{* *}$ & .139 & $.372^{* *}$ & .179 \\
\hline & Sig. (2-tailed) & & .005 & .002 & .280 & .003 & .164 \\
\hline & $\mathrm{N}$ & 62 & 62 & 62 & 62 & 62 & 62 \\
\hline \multirow{3}{*}{ IOT } & $\begin{array}{l}\text { Pearson } \\
\text { Correlation }\end{array}$ & $.350^{* *}$ & 1 & $.500^{* *}$ & $.654^{* *}$ & $.558^{* *}$ & $.661^{* *}$ \\
\hline & Sig. (2-tailed) & .005 & & .000 & .000 & .000 & .000 \\
\hline & $\mathrm{N}$ & 62 & 62 & 62 & 62 & 62 & 62 \\
\hline \multirow{3}{*}{ Coma } & $\begin{array}{l}\text { Pearson } \\
\text { Correlation }\end{array}$ & $.383^{* *}$ & $.500^{* *}$ & 1 & $.315^{*}$ & $.454^{* *}$ & $.330^{* *}$ \\
\hline & Sig. (2-tailed) & .002 & .000 & & .013 & .000 & .009 \\
\hline & $\mathrm{N}$ & 62 & 62 & 62 & 62 & 62 & 62 \\
\hline \multirow{3}{*}{$\begin{array}{l}\text { Cardio- } \\
\text { respiratory } \\
\text { stop }\end{array}$} & $\begin{array}{l}\text { Pearson } \\
\text { Correlation }\end{array}$ & .139 & $.654^{* *}$ & $.315^{*}$ & 1 & $.334^{* *}$ & $.866^{* *}$ \\
\hline & Sig. (2-tailed) & .280 & .000 & .013 & & .008 & .000 \\
\hline & $\mathrm{N}$ & 62 & 62 & 62 & 62 & 62 & 62 \\
\hline \multirow{3}{*}{$\begin{array}{l}\text { ATI } \\
\text { admission }\end{array}$} & $\begin{array}{l}\text { Pearson } \\
\text { Correlation }\end{array}$ & $.372^{* *}$ & $.558^{* *}$ & $.454^{* *}$ & $.334^{* *}$ & 1 & $.368^{* *}$ \\
\hline & Sig. (2-tailed) & .003 & .000 & .000 & .008 & & .003 \\
\hline & $\mathrm{N}$ & 62 & 62 & 62 & 62 & 62 & 62 \\
\hline \multirow{3}{*}{ Exitus } & $\begin{array}{l}\text { Pearson } \\
\text { Correlation }\end{array}$ & .179 & $.661^{* *}$ & $.330^{* *}$ & $.866^{* *}$ & $.368^{* *}$ & 1 \\
\hline & Sig. (2-tailed) & .164 & .000 & .009 & .000 & .003 & \\
\hline & $\mathrm{N}$ & 62 & 62 & 62 & 62 & 62 & 62 \\
\hline
\end{tabular}


TABLE 6. Pearson coefficients for identifying the correlations between the presentation times in the Toxicology Department and the unfavorable evolution parameters

\begin{tabular}{|c|c|c|c|c|c|c|c|c|}
\hline & & $\begin{array}{c}\text { Direct } \\
\text { presentation } \\
\text { time in } \\
\text { toxicology }\end{array}$ & $\begin{array}{l}\text { Transfer } \\
\text { time in } \\
\text { toxicology }\end{array}$ & IOT & Coma & $\begin{array}{l}\text { Cardio- } \\
\text { respiratory } \\
\text { stop }\end{array}$ & $\begin{array}{c}\text { ATI } \\
\text { admission }\end{array}$ & Exitus \\
\hline \multirow{3}{*}{$\begin{array}{l}\text { Direct } \\
\text { presentation } \\
\text { time in } \\
\text { toxicology }\end{array}$} & $\begin{array}{l}\text { Pearson } \\
\text { Correlation }\end{array}$ & 1 & $-.298^{*}$ & -.183 & -.252 & .123 & -.099 & -.114 \\
\hline & Sig. (2-tailed) & & .037 & .169 & .056 & .359 & .459 & .394 \\
\hline & $\mathrm{N}$ & 58 & 49 & 58 & 58 & 58 & 58 & 58 \\
\hline \multirow{3}{*}{$\begin{array}{l}\text { Transfer time in } \\
\text { toxicology }\end{array}$} & $\begin{array}{l}\text { Pearson } \\
\text { Correlation }\end{array}$ & $-.298^{*}$ & 1 & $.393^{* *}$ & $.313^{*}$ & .193 & .253 & .147 \\
\hline & Sig. (2-tailed) & .037 & & .005 & .029 & .183 & .080 & .313 \\
\hline & $\mathrm{N}$ & 49 & 49 & 49 & 49 & 49 & 49 & 49 \\
\hline \multirow{3}{*}{ IOT } & $\begin{array}{l}\text { Pearson } \\
\text { Correlation }\end{array}$ & -.183 & $.393^{* *}$ & 1 & $.500^{* *}$ & $.654^{* *}$ & $.558^{* *}$ & $.661^{* *}$ \\
\hline & Sig. (2-tailed) & .169 & .005 & & .000 & .000 & .000 & .000 \\
\hline & $\mathrm{N}$ & 58 & 49 & 62 & 62 & 62 & 62 & 62 \\
\hline \multirow{3}{*}{ Coma } & $\begin{array}{l}\text { Pearson } \\
\text { Correlation }\end{array}$ & -.252 & $.313^{*}$ & $.500^{* *}$ & 1 & $.315^{*}$ & $.454^{* *}$ & $.330^{* *}$ \\
\hline & Sig. (2-tailed) & .056 & .029 & .000 & & .013 & .000 & .009 \\
\hline & $\mathrm{N}$ & 58 & 49 & 62 & 62 & 62 & 62 & 62 \\
\hline \multirow{3}{*}{$\begin{array}{l}\text { Cardio- } \\
\text { respiratory } \\
\text { stop }\end{array}$} & $\begin{array}{l}\text { Pearson } \\
\text { Correlation }\end{array}$ & .123 & .193 & $.654^{* *}$ & $.315^{*}$ & 1 & $.334^{* *}$ & $.866^{* *}$ \\
\hline & Sig. (2-tailed) & .359 & .183 & .000 & .013 & & .008 & .000 \\
\hline & $\mathrm{N}$ & 58 & 49 & 62 & 62 & 62 & 62 & 62 \\
\hline \multirow{3}{*}{ ATI admission } & $\begin{array}{l}\text { Pearson } \\
\text { Correlation }\end{array}$ & -.099 & .253 & $.558^{* *}$ & $.454^{* *}$ & $.334^{* *}$ & 1 & $.368^{* *}$ \\
\hline & Sig. (2-tailed) & .459 & .080 & .000 & .000 & .008 & & .003 \\
\hline & $\mathrm{N}$ & 58 & 49 & 62 & 62 & 62 & 62 & 62 \\
\hline \multirow{3}{*}{ Exitus } & $\begin{array}{l}\text { Pearson } \\
\text { Correlation }\end{array}$ & -.114 & .147 & $.661^{* *}$ & $.330^{* *}$ & $.866^{* *}$ & $.368^{* *}$ & 1 \\
\hline & Sig. (2-tailed) & .394 & .313 & .000 & .009 & .000 & .003 & \\
\hline & $\mathrm{N}$ & 58 & 49 & 62 & 62 & 62 & 62 & 62 \\
\hline
\end{tabular}

duces hospitalization costs and inpatient mortality compared with situations when patients are cared for by doctors of other specialties [11].

A paper published in the Egyptian Journal of Forensic Sciences concluded that $13,5 \%$ of the 584 referred cases in this study were labeled as an inappropriate transfer. Some of the inadvertencies identified were: referred cases after an unjustified long delay time ( $>6 \mathrm{~h}$ ), inappropriately transported cases, or referred cases while risks of transfer outweighed its benefits [12].

Medical literature has evidence that when the doctor from the antitoxic center suggests an unfamiliar or too complex approach for the treating physician's experience or lacks medical resources, the recommendations will be followed in less than two-thirds of cases. Also, the patient's clinical data in the territorial hospital may differ or may not be accessible to the regional center because the patient's bed examination is more precise than the remote toxicologist's. Therefore, many medical situations can not be managed accurately on the phone [4].
To highlight the limitations of the strategies not to transfer patients to a regional center and just follow the recommendations of a toxicology expert by phone, some simulations with cases of poisoning have been made. Thus, the advice received from the antitoxic or regional centers was adequate in only $42-60 \%$ of the situations [4].

Considering both scriptwriters and the results presented, the decision to transfer a patient to a hospital with a toxicology department needs to consider the risks determined in this study or continuing an inappropriate treatment.

\section{CONCLUSIONS}

In this paper, to assess the influence of the timelapse between toxic exposure and toxicological examination on the patient's evolution, a sample of 50 poisoned cases with cardiotoxic agents associating signs of cardiogenic shock was used. These patients have been divided into two groups; one came directly to the toxicology department, whereas the rest were referred 
from a territorial hospital. There is no statistically significant difference between the mean times for the first examination, regardless of the medical care unit's rank. However, the time-lapse between toxic exposure and the toxicological examination is about twofold larger for the referred group.

The Pearson coefficient, used to analyze whether the time difference between the two groups is associated with unfavorable evolution, revealed that the referred group has a significantly higher risk of evolving to coma, being intubated and mechanically ventilated, or requiring admission in the ICU.
Even facing the arguments saying that care in a territorial hospital will be perhaps an inadequate one, transferring the patient to a regional center may endanger the lives of unstable patients, so is revealed in the statistical analysis performed.

Thus, facing the two alternatives sustained by solid arguments that imply vital decisions, they should be adequately assessed and individualized, considering each case's particularities.

Conflict of interest: none declared Financial support: none declared

\section{REFERENCES}

1. Vivisenco $\mathrm{Cl}$, Ulmeanu CE. Acute poisoning with cardiotropic agents in children - clinical and paraclinical features. Ro $\mathrm{J}$ Med Pract. 2013;8(3):183-8.

2. Enache CD, et al. Predictive score of the necessity for inotropic vasopressor support in children with acute poisoning with cardiotoxic substances. E-Health and Bioengineering Conference (EHB), 2019:1-4

3. Abbott MB, Vlasses $\mathrm{CH}$. Nelson Textbook of Pediatrics. JAMA. 2011;306(21):2387-2388.

4. Brent J, Burkhart K, Dargan P, Hatten B, Mégarbane B, Palmer R, White J (eds.). Critical care toxicology: Diagnosis and management of the critically poisoned patient. Springer, 2017.
5. Stanca S, Petran M, Ulmeanu C, Nitescu V. Toxic coma in children - etiology and clinical diagnosis. Therapeutics, Pharmacology \& Clinical Toxicology 2011;15(1).

6. Seritan GC, et al. Guidelines for small size samples biostatistics in current medical practice. E-Health and Bioengineering Conference (EHB), 2019.

7. Brissaud O, Botte A, Cambonie G, Dauger $S$, de Saint Blanquat L, et al. Experts' recommendations for the management of cardiogenic shock in children. Ann Intensive Care. 2016 Dec;6(1):14.

8. Liu HL, et al. Prediction of early mortality in patients with paraquat intoxication. Journal of Acute Medicine 2013;3(1):6-10.
9. Collins T. Understanding shock. Nursing Standard. 2000;14(49):35-39.

10. Yang L, Fan Y, Lin R, He W. Blood Lactate as a Reliable Marker for Mortality of Pediatric Refractory Cardiogenic Shock Requiring Extracorporeal Membrane Oxygenation. Pediatr Cardiol. 2019 Mar;40(3):602-609.

11. Hasdai D. Cardiogenic Shock. Springer, 2002:3-6.

12. Masry MK, Azab MS. Inappropriate management and transfer of cases with acute poisoning referred to poisoning treatment center - Ain Shams University - Cairo. Egyptian Journal of Forensic Sciences 2013;3(1):1-7. 